\title{
Factors Influencing Outcomes of Children Hospitalized with Acute Severe Malnutrition
}

\author{
Viramitha Kusnandi, ${ }^{1}$ Siska Wiramihardja, ${ }^{2}$ Adhitya AP, ${ }^{1}$ Dida A Gurnida ${ }^{1}$ \\ ${ }^{1}$ Department of Child Health Faculty of Medicine Universitas Padjadjaran/Dr. Hasan Sadikin \\ General Hospital Bandung, Indonesia, ${ }^{2}$ Departement of Public Helath Faculty of Medicine \\ Universitas Padjadjaran, Indonesia
}

\begin{abstract}
Background: Nutrition is still a global health issue, and improving nutrition is among the targets of the Sustainable Developmental Goals (SDGs). One of Indonesia's SDGs indicators is to reduce prevalence of malnutrition in children. Indonesia, as a developing country, implements a comprehensive malnutrition treatment program for children, including various aspects related to management of children with acute malnutrition. The purpose of this study was to identify factors associated with the outcome of children hospitalized with acute severe malnutrition.

Methods: This cross sectional study enrolled 195 children with severe acute malnutrition, admitted to hospital from November 2016 to August 2017. Statistical Analysis was conducted using multivariable logistic regression to identify factors associated with the outcome. Adjusted Ratio with Confident Interval $95 \%$ and the value of $\mathrm{P}<0.05$ was considered significant.

Result: A total of 195 children were diagnosed havings acute severe malnutrition. A history of complete immunization status ( $\mathrm{p}$ value $<0.001$ ) was proved to be directly proportional to the recovery rate of patients with acute severe malnutrition. Provision of other types of antibiotic ( $\mathrm{p}$ value 0.001 ) showed to increase recovery rates of patients with acute severe malnutrition. Several comorbid diseases reduced recovery rates such as pneumonia (Crude OR 0.619) tuberculosis (Crude OR 0.606) and HIV (p value 0.08).

Conclusions: This study shows that although the provided treatments are appropriate with the standard treatment for severe malnutrition, they still encounter high levels of morbidity. Further large-scale studies should be conducted to develop better interventions and management of acute severe malnutrition, in order to achieve better outcome.
\end{abstract}

Keywords: Children, related factors, outcome, severe acute malnutrition

\section{Introduction}

Adequate nutrition is a fundamental human right and is a prerequisite for good health. Malnutrition is still one of the most common causes of morbidity and mortality among children worldwide, especially in the regions of sub-Saharan Africa and Asia. Severe acute malnutrition (SAM) causes approximately 1-2 million deaths each year, with 20 million living in a state of severe acute malnutrition. ${ }^{1,2}$ Malnutrition is associated with $>50 \%$ mortality in developing countries due to underlying infectious diseases. ${ }^{3}$ Several diseases that often accompanies children with malnutrition and increase mortality are: diarrhea $60.7 \%$, pneumonia $52, \%$, measles $44.8 \%$ and malaria

\section{$57.3 \% \%^{3,4}$}

Approximately $2 \%$ of children in developing countries suffer from SAM, especially in South Asian countries and Sub-Saharan Africa. Acute severe malnutrition is a common comorbid of children admitted to the hospital. ${ }^{5-7}$ This underlying condition may cause death up to 25 to $30 \%$ of children in many poor countries. 6 Previous studies suggest that approximately 12 million children under the age of five die every year in developing countries, in which $60 \%$ was associated with malnutrition. ${ }^{8}$ Despite good progression in child health, severe acute malnutrition remains the leading cause of death in children under the age of five. ${ }^{7}$ SAM high mortality rate had remained a problem for the past few years. Several countries with

Correspondence: Viramitha Kusnandi, Department of Child Health, Faculty of Medicine Universitas Padjadjaran/Dr. Hasan Sadikin General Hospital Bandung, Indonesia, Email: virmith@yahoo.com 
high SAM prevalence have developed specific national policies in order to to formulate the strategies to solve malnutrition problem comprehensively. ${ }^{9}$

Currently, there are limited information on treatment outcome and clinical characteristics associated with mortality aiming to improve inpatient care of SAM. ${ }^{10}$ Therefore, this study aims to assess outcome status and factors influencing outcome in children with SAM admitted to the Department of Child Health Hasan Sadikin Hospital. ${ }^{4}$

\section{Methods}

This study was conducted in Bandung City, $\pm 150 \mathrm{~km}$ from Indonesia's capital, Jakarta, and is the largest city in West Java province with an estimated population of 2,500,000 inhabitants. This study was conducted at Dr. Hasan Sadikin Hospital, which is a provincial reference hospital that has a pediatric intraining study program.

Data was obtained from patient's medical records with prior approval from the Helath Research Ethics Committee and Medical Record Installation of Dr. Hasan Sadikin General Hospital. The inclusion criteria were based on WHO Child Growth Standard curve $<-3$ Z-score or if the patient had bilateral pitting edema or arm circumference <-3 Z-score. Criteria for improvements were based on the SPHERE international criteria, in which children returning from hospital present no symptoms of disease and are able to maintain or increase bodyweight (measured within 2 weighing times). ${ }^{4}$

This cross sectional study enrolled 195 children with acute severe malnutrition treated at the Department of Child Health, Dr. Hasan Sadikin General Hospital, since November 2016 to August 2017. Analysis using multivariable logistic regression was used to identify the factors associated with outcomes. Adjusted Ratio with 95\% CI and P-values less than 0.05 was considered significant. All data obtained were processed and analyzed using SPSS software version 16.

\section{Results}

The result of this study showed no association between gender, age, place of residence and exclusive breastfeeding with patient outcome ( $p>0.05)$. Interestingly, a significant positive correlation was observed between immunization and patient recovery. A total of
96 out of 152 recovered subjects had complete records and 33 out of 43 patients who did not recovered had complete records. Complete immunization status in the recovery group was $44.8 \%$, which was higher than the nonrecovered group (12.1\%) (Table 1).

Furthermore, in the non-recovered group, the most common comorbidities were pneumonia $44.2 \%$, anemia $32.6 \%$, and tuberculosis 20.9\%. From 152 recovered subjects $28.9 \%$ were given other antibiotics, while from 43 non recovered subjects, only $4.2 \%$ were given other antibiotics. In the nonrecovered group, $72.1 \%$ received folic acid supplementation and $58.1 \%$ received Fe which were significantly higher than the recovered group (52.6\% folic acid (p 0.023) and $28.3 \%$ Fe supplementation $(\mathrm{p}<0.001)$, respectively (Table 1).

Moreover, the bivariate analysis indicated that sex, age and residency did not show significant correlation with patient's outcome. However, the result implied that female, age $<2$ years and urban residence tend to have a higher chance of recovery.

This study revealed that complete immunization status had a 2-fold tendency to recover among children with acute severe malnutrition. Comorbid such as tuberculosis, pneumonia, anemia and sepsis showed an OR $<1$, suggesting reduced chance of recovery, but the results were not significant. Provision of other antibiotics influenced recovery 8-fold and was statistically significant. Multivitamin, folate and $\mathrm{Fe}$ supplementation results had $\mathrm{OR}<1$, meaning that it reduced the chances of recovery, especially Folate and Fe which was significant.

\section{Discussion}

This study included 195 children treated in the pediatric ward of Dr. Hasan Sadikin Hospital Bandung. This study showed no significant differences in sex among all patients with acute severe malnutrition. The ratio of male and female is 115 to 80 . Most of the patients were above 5 years old, comprising almost half of the study subjects. A number of research and management in the field of healthcare has continued to increase, aiming to improve recovery rate. Malnutrition in children leads to weakened immunity and plays a large role in the high mortality rates observed among children in sub-Saharan Africa and south Asia. ${ }^{11,12}$ Acute severe malnutrition is a global problem especially in developing countries such as Indonesia. 
Table 1 Basic Characteristics of Subject

\begin{tabular}{|c|c|c|c|c|}
\hline & $\begin{array}{c}\text { Total } \\
\mathrm{n}=195\end{array}$ & $\begin{array}{c}\text { Recovered } \\
\mathrm{n}=152\end{array}$ & $\begin{array}{c}\text { Not recovered } \\
n=43\end{array}$ & p-value \\
\hline \multicolumn{5}{|l|}{ Gender } \\
\hline Male & $115(59.0)$ & $89(58.6)$ & $26(60.5)$ & 0.822 \\
\hline Female & $80(41.0)$ & $63(41.4)$ & $17(39.5)$ & \\
\hline \multicolumn{5}{|l|}{ Age } \\
\hline$<2$ years old & $59(30.3)$ & $46(30.3)$ & $13(30.2)$ & 0.255 \\
\hline $2-5$ years old & $54(27.7)$ & $46(30.3)$ & $8(18,)$. & \\
\hline$>5$ years old. & $82(42.1)$ & $60(39.4)$ & $22(51.2)$ & \\
\hline \multicolumn{5}{|l|}{ Residence } \\
\hline Rural & $99(50.8)$ & 74 (48.7) & 25 (58.1) & 0.274 \\
\hline Urban & $96(49.2)$ & $78(51.3)$ & $18(41.9)$ & \\
\hline Exclusive Breastfeeding & $n=9$ & $\mathrm{n}=9$ & & \\
\hline Not breastfeeded & $3(33.3)$ & $3(33.3)$ & & \\
\hline 6 months & $4(44.4)$ & $4(44.4)$ & & \\
\hline 2 years & $2(22.2)$ & $2(22.2)$ & & \\
\hline Immunization Status & $n=129$ & $n=96$ & $n=33$ & \\
\hline Measles & $63(48.8)$ & $37(38.5)$ & $26(78.8)$ & $<0.001^{*}$ \\
\hline Complete & $47(36.4)$ & $43(44.8)$ & $4(12.1)$ & \\
\hline Incomplete & $19(14.7)$ & $16(16.7)$ & $3(9.1)$ & \\
\hline \multicolumn{5}{|l|}{ Comorbid } \\
\hline Diarrhea & $18(9.2)$ & $16(10.5)$ & $2(4.7)$ & 0.372 \\
\hline TBC & $30(15.4)$ & $21(13.8)$ & $9(20.9)$ & 0.254 \\
\hline HIV & $2(1.0)$ & $0(0.0)$ & $2(4.7)$ & $0.048^{*}$ \\
\hline Pneumonia & $69(35.4)$ & $50(32.9)$ & $19(44.2)$ & 0.172 \\
\hline Anemia & $61(31.3)$ & 47 (30.9) & $14(32.6)$ & 0.838 \\
\hline CHF & $8(4.1)$ & $7(4.6)$ & $1(2.3)$ & 0.688 \\
\hline Sepsis & $22(11.3)$ & $16(10.5)$ & $6(14.0)$ & 0.586 \\
\hline Head Circumference & $n=64$ & $\mathrm{n}=49$ & $n=15$ & \\
\hline Normosefal & $24(37.5)$ & $19(38.8)$ & $5(33.3)$ & 0.930 \\
\hline Mikrosefal & $36(56.3)$ & $27(55.1)$ & $9(60.0)$ & \\
\hline Makrosefal & $4(6.3)$ & $3(6.1)$ & $1(6.7)$ & \\
\hline \multicolumn{5}{|l|}{ Treatment } \\
\hline Amoxicillin & $10(5.1)$ & $10(6.6)$ & $0(0.0)$ & 0.121 \\
\hline Ampicillin-Gentamisin & $99(50.8)$ & $72(47.4)$ & $27(62.8)$ & 0.074 \\
\hline Other Antibiotics & $46(23.6)$ & $44(28.9)$ & $2(4.7)$ & $0.001^{*}$ \\
\hline \multicolumn{5}{|l|}{ Supplements } \\
\hline Multivitamin & $93(47.7)$ & $69(45.4)$ & $24(55.8)$ & 0.227 \\
\hline Folat & $111(56.9)$ & $80(52.6)$ & $31(72.1)$ & $0.023^{*}$ \\
\hline $\mathrm{Fe}$ & 68 (34.9) & 43 (28.3) & 25 (58.1) & $<0.001^{*}$ \\
\hline
\end{tabular}


Table 2 Bivariate Analysis of Logistic Regression Factors Affecting the Output

\begin{tabular}{|c|c|c|}
\hline & Crude OR (95\% CI) & p-value \\
\hline \multicolumn{3}{|l|}{ Gender } \\
\hline Male & 1 & \\
\hline Female & $1.083(0.542-2.161)$ & 0.822 \\
\hline \multicolumn{3}{|l|}{ Age } \\
\hline$<2$ years old & 1 & \\
\hline 2-5 years old & $1.297(0.591-2.847)$ & 0.516 \\
\hline$>5$ years old & $2.108(0.861-5.164)$ & 0.103 \\
\hline \multicolumn{3}{|l|}{ Residence } \\
\hline Rural & 1 & \\
\hline Urban & $1.464(0.739-2.902)$ & 0.275 \\
\hline \multicolumn{3}{|l|}{ Immunization Status } \\
\hline Measles & 1 & \\
\hline Complete & $0.267(0.070-1.010)$ & 0.052 \\
\hline Incomplete & $2.016(0.406-10.016)$ & 0.391 \\
\hline \multicolumn{3}{|l|}{ Comorbid } \\
\hline Diarrhea & $2.412(0.532-10.972)$ & 0.253 \\
\hline TBC & $0.606(0.254-1.441)$ & 0.257 \\
\hline HIV & - & - \\
\hline Pneumonia & $0.619(0.310-1.235)$ & 0.174 \\
\hline Anemia & $0.927(0.449-1.914)$ & 0.838 \\
\hline $\mathrm{CHF}$ & $2.028(0.243-16.947)$ & 0.514 \\
\hline Sepsis & $0.725(0.265-1.984)$ & 0.532 \\
\hline \multicolumn{3}{|l|}{ Treatment } \\
\hline Amoxicillin & - & - \\
\hline Ampicillin-Gentamisin & $0.533(0.266-1.069)$ & 0.076 \\
\hline Other Antibiotics & $8.352(1.936-36.033)$ & $0.004^{*}$ \\
\hline \multicolumn{3}{|l|}{ Supplements } \\
\hline Multivitamin & $0.658(0.333-1.301)$ & 0.229 \\
\hline Folat & $0.430(0.206-0.900)$ & $0.025^{*}$ \\
\hline $\mathrm{Fe}$ & $0.284(0.141-0.573)$ & $<0.001^{*}$ \\
\hline
\end{tabular}

This study showed a recovery rate of $77.9 \%$, slightly exceeding the minimum value of international standards to monitor recovery rates which is more than $75 \%{ }^{4,13}$ These results are similar with results obtained by Jimma University, which show a result of $77.8 \%{ }^{4}$ These results provide notice that the recovery rate of children with acute severe malnutrition is still low, therefore an intervention program is needed to improve welfare and health of the child in the future. ${ }^{14}$

The differences in recovery outcomes may be influenced by socioeconomic status, quality of treatment, clean and healthy life behavior, access to supplementary food and health services, and finally the difference in malnutrition management guidelines in each area. The study in Africa conducted by Grebemichael et al. ${ }^{10}$ shows similar results. The study reported that socio-demographic factors 
such as age and residence are not associated with recovery rates, however immunization status is proportionally correlated with severe acute malnutrition in children. ${ }^{14}$

Furthermore, pneumonia occurred in $35 \%$ of SAM patients, pneumonia is the most frequent comorbid disease suffered by the subjects. The incidence of pneumonia is still high in Indonesia, data from a study conducted by Rudan et al. in Tan et.al ${ }^{15}$ showed that 450.611 episodes of lower respiratory tract infection in children $<5$ years old are caused by Streptococcus infection Pneumonia. Rudan et al. in Tan et al. ${ }^{15}$ also showed that in Surabaya and Denpasar are 283 cases/100,000 children and 347 cases $/ 100,000$ children.

The low recovery rate obtained in this study might be due to the lack of data and limited amount of subjects. In addition, low immunization coverage also contributes to the recovery rate of children with severe acute malnutrition. The study was conducted at a tertiary referral hospital, therefore many patients had a severe comorbid such as tuberculosis, congenital heart disease, hemato-oncology and HIV malignancies, all which have an effect on the recovery rate of hospitalized patients.

Similar outcomes was reported by a retrospective cohort study conducted in southern Africa, in which socio-demographic characteristics such as age, place of residence, and breastfeeding status are not statistically associated with recovery rates. However, immunization status and use of other antibiotics are statistically correlated. ${ }^{10}$

Moreover, the probability of recovery rate of patients with comorbid decreases, that was also found in studies conducted at Jimma University, which reported low recovery rate and increase chance of mortality among patients with comorbid. ${ }^{16}$ The reason behind this might be due to longer admission period, severe decline of nutrition status, and higher demand for nutrition. However, intake, absorption, and utilization remains low. ${ }^{10,16}$

Other comorbid studies are patients with HIV / AIDS and TB who have a lower recovery rates than patients without HIV / AIDS and TB. The percentage of people with HIV and TB in this study are $1 \%$ and $15.4 \%$ respectively. This study has similar results as those done by Collins et al. ${ }^{17}$

The limitations of this study are the lack of comparison with other studies conducted in other health facilities within the same area; lack of information on the study subject because the study relied on medical record records; and the lack of appropriate statistical method to use in a small sample. ${ }^{4}$

It can be concluded that there is an association of factors that alleviate and increase the morbidity and mortality of acute severe malnutrition in children. Based on this research, the patient's complete immunization status and measles immunization was found to correlate with better recovery rates, while the provision of multivitamin, folic acid and $\mathrm{Fe}$ supplements reduces the chance of recovery. The use of other choices of antibiotics is also a factor that may have more influence on the recovery rate than the provision of ampicillin and gentamicin and when not given antibiotics. Additionally, HIV infection, pneumonia and tuberculosis are comorbid factors that exacerbate acute severe malnutrition.

\section{References}

1. Jarso H, Workicho A, Alemseged F. Survival status and predictors of mortality in severely malnourished children admitted to Jimma University Specialized Hospital from 2010 to 2012, Jimma, Ethiopia: a retrospective longitudinal study. BMC Pediatr. 2015;15(1):76.

2. Mekuria G, Derese T, Hailu G. Treatment outcome and associated factors of severe acute malnutrition among 6-59 months old children in Debre Markos and Finote Selam hospitals, Northwest Ethiopia: a retrospective cohort study. BMC Nutrition. 2017;3(1):42.

3. Berti A, Bregani ER, Manenti F, Pizzi C. Outcome of severely malnourished children treated according to UNICEF 2004 guidelines: a one-year experience in a zone hospital in rural Ethiopia. Trans $\mathrm{R}$ Soc Trop Med Hyg. 2008;102(9):939-44.

4. Desyibelew HD, Fekadu A, Woldie H. Recovery rate and associated factors of children age 6 to 59 months admitted with severe acute malnutrition at inpatient unit of Bahir Dar Felege Hiwot Referral hospital therapeutic feeding unite, northwest Ethiopia. PloS One. 2017;12(2):e0171020.

5. Dereje N. Determinants of severe acute malnutrition among under five children in Shashogo Woreda, Southern Ethiopia: a community based matched case control study. J Nutr Food Sci. 2014;4(5):300

6. Shanka N, Lemma S, Abyu D. Recovery rate and determinants in treatment of children with severe acute malnutrition using outpatient therapeutic feeding program in Kamba District, South West Ethiopia. J 
Nutr Disorders Ther. 2015;5(2):155

7. Lijalem M, Ahmed A, Mulate A, Asmare A, Bahiru K. Severity of malnutrition and treatment responses in under five children in Bahir Dar Felege Hiwot Referral Hospital, Northwest Ethiopia. J Food Nutr Sci. 2014;2(3):93-8.

8. Chane T, Oljira L, Atomesa GE, Agedew E. Treatment outcome and associated factors among under-five children with severe acute malnutrition admitted to therapeutic feeding unit in Woldia hospital, North Ethiopia. J Nutr Food Sci. 2014;4(6):329.

9. Ahmed S, Ejaz K, Mehnaz A, Adil F. Implementing WHO Feeding Guidelines for Inpatient Management of Malnourished Children. J College Physicians Surg Pak. 2014;24(7):493-7.

10. Gebremichael DY. Predictors of nutritional recovery time and survival status among children with severe acute malnutrition who have been managed in therapeutic feeding centers, Southern Ethiopia: retrospective cohort study. BMC Public Health. 2015;15(1):1267.

11. Black RE, Morris SS, Bryce J. Where and why are 10 million children dying every year? Lancet. 2003;361(9376):2226-34.

12. Munthali T, Jacobs C, Sitali L, Dambe R, Michelo C. Mortality and morbidity patterns in under-five children with severe acute malnutrition (SAM) in Zambia: a five-year retrospective review of hospitalbased records (2009-2013). Arch Public Health. 2015;73(1):23.

13. Van Zutphen T. Sphere project: humanitarian charter and minimum standards in humanitarian response. Rugby,Warwickshire, UK: Practical Action Publishing; 2011.

14. Mbaya D, Bitok LK, Karani AK, Osano B, Habtu M. Outcomes of severely malnourished children aged 6-59 months on outpatient management program in Kitui County Hospital, Kenya. Open Journal of Child Health. 2015;5(04):326-33.

15. Tan KK, Dang DA, Kim KH, Kartasasmita C, Kim HM, Zhang X-H, et al. Burden of hospitalized childhood communityacquired pneumonia: A retrospective cross-sectional study in Vietnam, Malaysia, Indonesia and the Republic of Korea. Hum Vaccine Immunother. 2018:14(1):95-105.

16. Singh K, Badgaiyan N, Ranjan A, Dixit H, Kaushik A, Kushwaha K, et al. Management of children with severe acute malnutrition: Experience of nutrition rehabilitation centers in Uttar Pradesh, India. Indian Pediatr. 2014;51(1):21-5.

17. Collins S, Dent N, Binns P, Bahwere P, Sadler K, Hallam A. Management of severe acute malnutrition in children. Lancet. 2006;368(9551):1992-2000. 